\title{
THE EVALUATION OF ENTERPRISE APPLICATION INTEGRATION APPROACHES TO RESOLVE POSTAL PARCEL DELIVERY TRANSPORT ROUTING PROBLEMS LIETOJUMPROGRAMMATÜRAS INTEGRĀCIJAS RISINĀJUMU

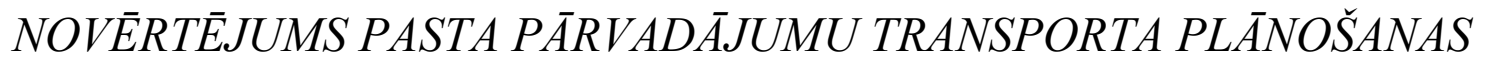 PROBLEMUU RISINĀ̄
}

\author{
Mārtiņš Bonders \\ Institute of Information Technology, Riga Technical University, \\ 1 Kalku Street, Riga, LV 1658, Latvia \\ Ph: +(371)6872638, fax:+(371)659408, e-mail: martins@iti.rtu.lv
}

\begin{abstract}
Information Technologies (IT) create interconnected application software. Nowadays, one of the vital problems is the enterprise application software integration. Systems of the transport routing become more complicated, because in order to efficiently solve transport routing and planning problems, it is necessary to get more and more information. Enterprise application methods and technologies allow to create effective transport routing system. To structure integration solutions, can be used different options and solutions, as well as platform of integration, but vital problem is the choice of the most suitable integration approach.

The aim of this paper is to evaluate several accessible integration solutions. Integration options are identified and classified according to integration approach and technologies used in this paper. In practical assessment of integration technologies, post parcel delivery and routing process is used as an example, for which it is necessary to create effective GPS/GIS/ERP integration solution. For this problem, several alternative solutions have been developed. They have been evaluated according to their high-speed, easily of development and modification, as well as other parameters.
\end{abstract}

Keywords: Integration, transport planning, parcel delivery.

\section{Introduction}

The paper investigates application integration for postal services. The problem of postal application integration is very complicated. One sub-topic of this problem is how to manage postal pick-up and delivery operations effectively and to rout delivery vehicles to pick-up or deliver parcels. At first, we must take a look on integration, what it does and what we can get from it.

An enterprise typically has many of applications that are custom built, acquired from a third party, part of a legacy systems or a combination. The applications operate in multiple tiers of different operating system platforms [1]. There are many ways, how we can define application integration. One of these is: Application integration is the secure and orchestrated sharing of processes and/or data between applications within the enterprise.

In general, we can highlight the following integration types: loose versus full integration, horizontal versus vertical integration, intra-enterprise versus inter-enterprise integration, system versus application versus business integration [4].

Using loose integration two systems are loosely integrated if they can merely exchange information with one another with no guarantee that they will interpret this information that same way, they are just connected and coexist in a larger system. Using full integration, systems are fully integrated and specificities of any one of these systems are only known to the system itself and not by the other one, the two systems both contribute to a common task and share the same definition o each concept they exchange. Horizontal integration concerns physical and logical integration of business processes from product demand to product 
shipment, but vertical integration concerns integration between the various management levels of the enterprise. Integration of the business processes internal to a give enterprise mean intra-enterprise integration, but integration of business processes of a give enterprise with business processes of other enterprises, mean inter-enterprise integration. Physical system integration essentially concerns systems communication, interconnection and data exchange by means of computer networks and communications protocols [4].

In the postal pick-up and delivery problem, most likely we can use something of intraenterprise, inter-enterprise, system and application integration. In general, to realize this complex integration architecture and connect together main integration point, we can use services.

If we look on integration from another side, we can see different approaches. Application integration concerns interoperability shared data by various applications. Finally business integration concerns integration at the enterprise level - business process coordination.

Integration problems arise from different perspectives: integration of markets, integration between several development and manufacturing sites, integration between suppliers and manufacturers, integration of design and manufacturing and integration of multi-vendor hardware and software components. [4] From these perspectives comes out deeper purposes usage as data integration, process integration, vendor integration and common facade.

Most enterprise integration projects generally fall into one of these project categories: enterprise application integration (EAI), business-to-business integration (B2Bi), Web integration, information portals, data replication, shared business functions, service-oriented architecture, and distributed business processes [1,2].

Application integration can be broadly categorized into three types: manual application integration, semi-automated application integration, fully automated application integration.

Manual application integration includes higher labor costs that scale badly and subject to human errors, but required little change from existing low-technology environment. Semiautomated includes higher technology costs to implement and subject to design-times and run-time errors, but requires lower labor costs scales better and give faster processing. Fully automated application integration includes highest technology costs to implement integration and subject to design errors. This type of integration includes lowest labor costs, does not have subject to human errors at run time and lose human decision making on business processes, but faster processing [3]. A postal service main control service must be a fully automated application integration service; the human part is only pick-up/delivery data registering. All other services must be fully automated, especially vehicle routing service.

Nowadays, we can implement application integration in a wide variety of ways. Common choices include miscellaneous services, ETL (Extract, Transform and Load), communications message protocols, program calls, direct data access, file transfer and only sometimes human involvement. Application integration can occur at many different levels; the most popular are presentation level, business process levels, data levels and communication level [3].

As we can see, integration seems to be very complicated process; therefore we must exactly know what we must integrate. If we look at the postal problem, we must know, how the pickup requests are received, recorded, delivered to the next point - sequence, route and time planning. How the routing part can get the information from GIS system, how the data are sent to routing algorithm, how the information are represented on the map and how the planned information is delivered to the postal cars and how we can manage pick-up and delivery process on-line.

The next section introduces specific issues of parcel delivery services and potentially best integration solutions to resolve this specifically problem more effective. The following sections will describe the integration requirement, most important steps, will give some 
integration solution examples and comparison chart. Some conclusions are pointed out at the results section.

\section{Materials and methods}

To manage postal pick-up and delivery operations more effectively, geographical information system (GIS), global positioning system (GPS), postal information system and wireless communications technologies must be successfully integrated. The goal of the effective parcel delivery service is proper transport logistics and flexible routing algorithm. This area is a typical example of a highly complex and time-critical business environment. This part of logistic problem is usually known as the vehicle routing problem (VRP) [8]. The main problem is to minimize the cost expressed as a combination of distance, time and /or money. As example, emergency fleet management is an example where the service time becomes a major challenge. Real-Time Decision Tools for the VRP must combine GPS information, GIS technology, on-line electronic data interchange, Web servers and efficient optimization algorithms in order to cope with parcels delivery needs. Very important requirement for this real-time decision system is possibility of decision tools to react in real-time [5]. The actual situation is shown in Figure 1.

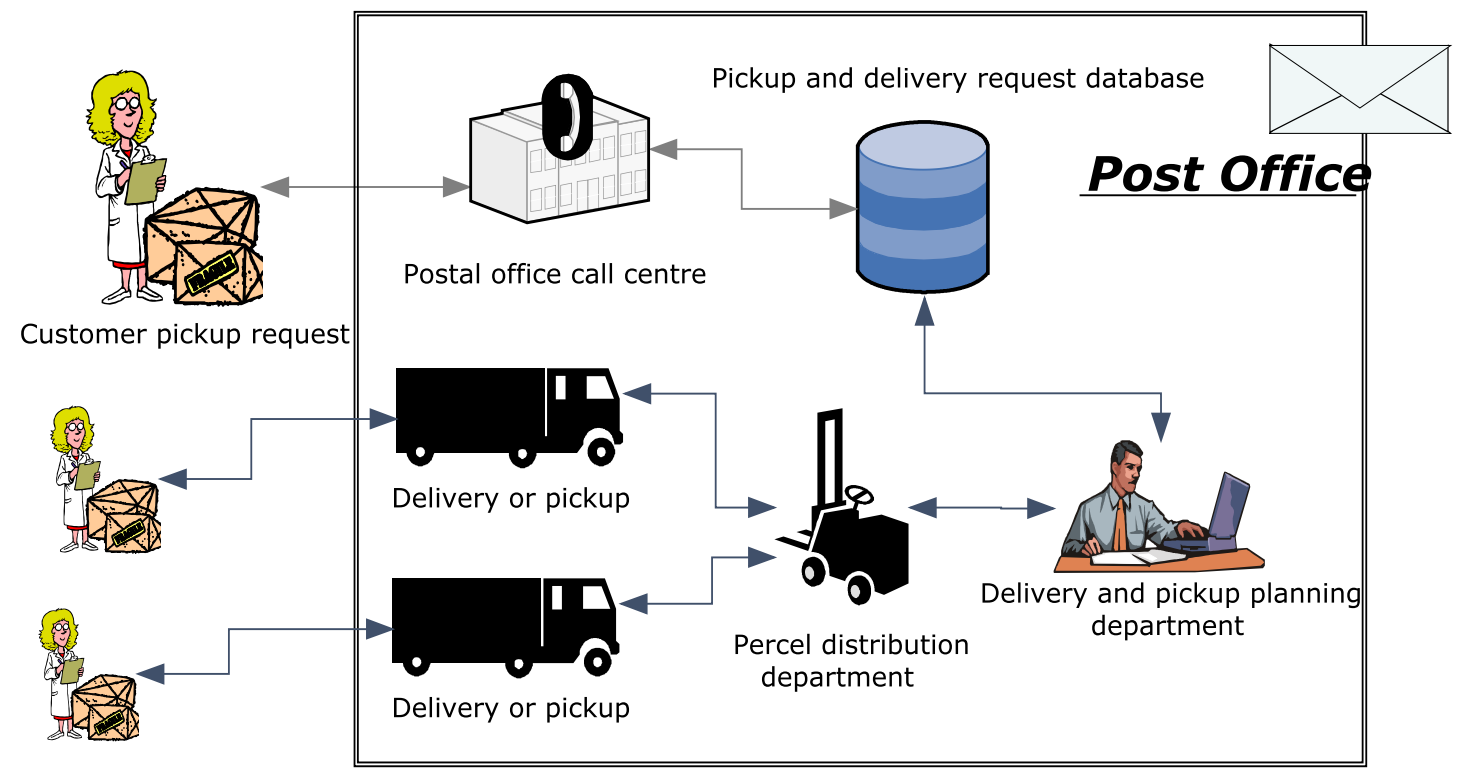

Fig. 1. The real situation of parcel management

As it can be observed, the actual situation has several shortcomings. Parcel delivery and pickup is planned by human working at the delivery and pickup planning department. This is time-consuming process. We cannot see where the postal delivery and pickup machines actually are, therefore in the case of exceptions, changing the routing is difficult.

For maximum performance we need intelligent monitoring and control system. When customer requests pick-up to the call center, the pick-up request information goes to the monitoring center server through the post office server, then this server performs address correction and sequence planning automatically. The main function of this intelligent monitoring system are routing and trace of vehicle, verification of pick-up and delivery results, verification of pick-up and delivery location, navigation, information upload from PDA about pick-up/delivery results and etc. This intelligent monitoring system consists of three main subsystems: pick-up/delivery sequence planning system, pick-up/delivery monitoring system, and PDA execution system. All these system parts communicate using unique services. The main problem is to create pick-up and delivery sequence and time 
schedule with the several input/output parameters and constraints. The objectives of the problem are to minimize the total duration times and travel times of all routes, make pickup/delivery process more flexible. As an example, input used in this system is local post office, pick-up/delivery request, time windows and time/distance by GIS. Output is pick-up and delivery sequence and time schedule. As constraints we must use time window, postman working time, post office revisit during post delivery, priority between customers, therefore communication between the system parts must be well organized and clear [6]. We must use separate services, that answering about unique data flow. This intelligent system model is depicted in Fig. 2.

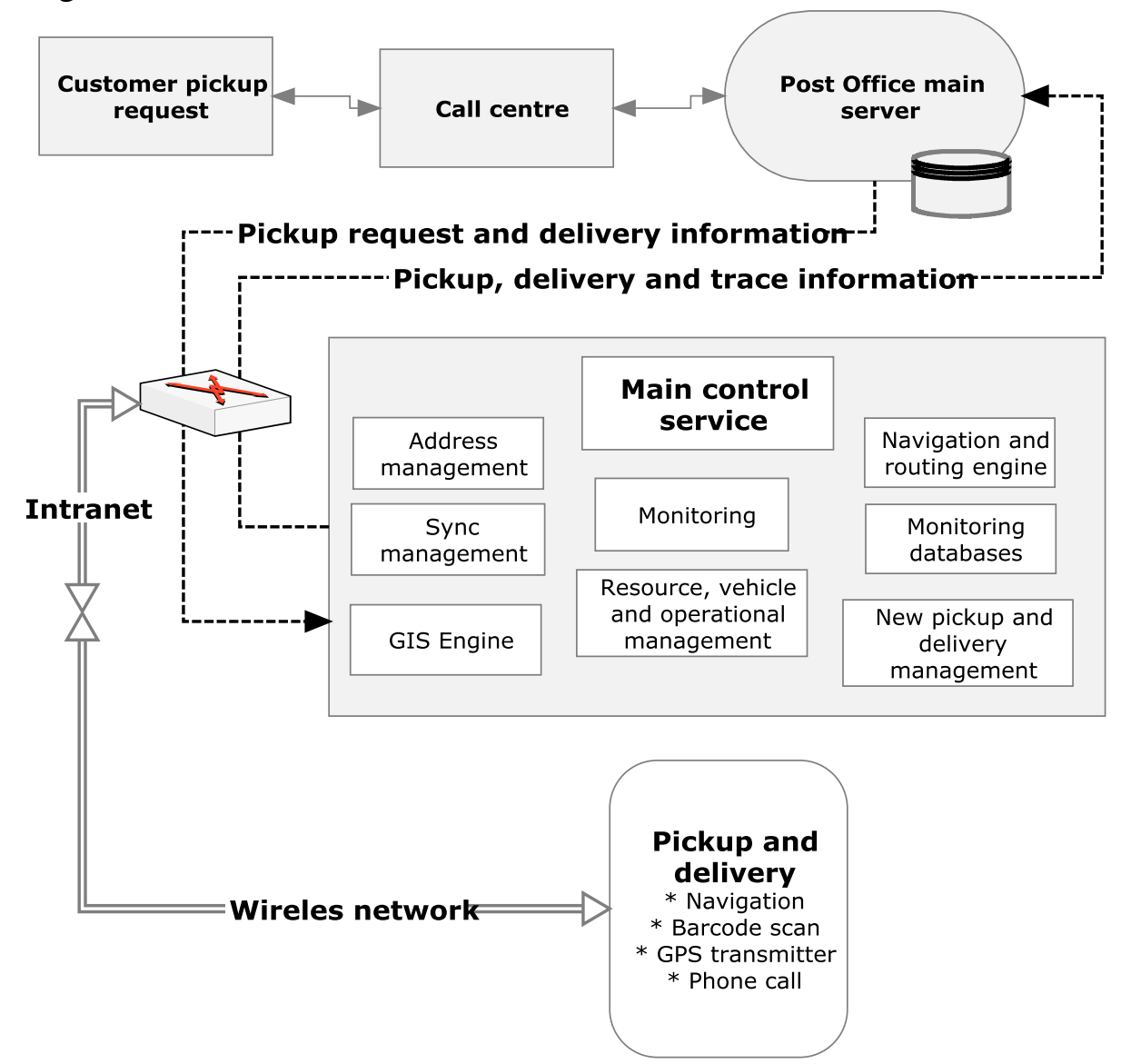

Fig. 2. Intelligent post control system

To realize described intelligent system model, we can categorize available and suitable integration approaches into three types. These types are included in Table 1.

Service integration is the best way to create a flexible route planning module. It is more easily to integrate all needed components and if we need, we can change these components and all integration schemes more flexible than using data or process integration.

\section{Results}

However, generally integration will be based on service integration, but in some cases it will be needed to use process integration. As we can see in Table 2, well know service function correspond to relevant standards and when we formalize what service function we will need, according to relevant standards we can find best way of integration. Almost all integration approach has standards what they use. For example, Microsoft BizTalk is a business process management (BPM) server and it uses adapters to communicate with different software systems. BizTalk uses such standards as WSDL, BPEL, SOAP, as we can see, if we must use 
and integrate our implementation using process services and enterprise service bus, one of the tools that we can to apply is Microsoft BizTalk [7].

Table 1.

Main integration standards for routing engine

\begin{tabular}{|l|l|l|l|}
\hline \multicolumn{1}{|c|}{ Type } & \multicolumn{1}{|c|}{ Definition } & \multicolumn{1}{c|}{ Advantage } & \multicolumn{1}{c|}{ Disadvantage } \\
\hline $\begin{array}{l}\text { Service } \\
\text { integration }\end{array}$ & $\begin{array}{l}\text { Process of combining } \\
\text { different software using } \\
\text { services provided by this } \\
\text { possibly distributed } \\
\text { software packages. As } \\
\text { example - web services, } \\
\text { executable business } \\
\text { processes, UDDI. }\end{array}$ & $\begin{array}{l}\text { Integration can be } \\
\text { realized using various } \\
\text { services and } \\
\text { application can be } \\
\text { located at several } \\
\text { servers and places. } \\
\text { Standardized business } \\
\text { process language } \\
\text { BPEL can be used. }\end{array}$ & $\begin{array}{l}\text { Service integration } \\
\text { technology approach is a } \\
\text { relatively new } \\
\text { technology; data } \\
\text { accessibility depends on } \\
\text { many factors - network } \\
\text { speed, hardware } \\
\text { productivity and } \\
\text { application speed. }\end{array}$ \\
\hline Data integration & $\begin{array}{l}\text { Process of } \\
\text { combining data residing at } \\
\text { different sources and } \\
\text { providing the user with a } \\
\text { unified view of these data. } \\
\text { As example - XML, } \\
\text { schema integration, data } \\
\text { bases integration. }\end{array}$ & $\begin{array}{l}\text { Relatively easy } \\
\text { integration } \\
\text { technology, can be } \\
\text { used various data } \\
\text { schemas }\end{array}$ & $\begin{array}{l}\text { Problems with real-time } \\
\text { data processing, data } \\
\text { types }\end{array}$ \\
\hline $\begin{array}{l}\text { Process } \\
\text { integration }\end{array}$ & $\begin{array}{l}\text { different software using } \\
\text { access to processes through } \\
\text { specific connectors. As } \\
\text { example - unique } \\
\text { components, COM, J2EE. }\end{array}$ & $\begin{array}{l}\text { Can be integrated all } \\
\text { process as one }\end{array}$ & $\begin{array}{l}\text { Not all application } \\
\text { provide specific } \\
\text { connectors for accessing } \\
\text { data }\end{array}$ \\
& \multicolumn{2}{|l}{} \\
\hline
\end{tabular}

Service functions and their relevant standards

\begin{tabular}{|l|l|}
\hline \multicolumn{1}{|c|}{ Service function } & \multicolumn{1}{c|}{ Relevant standards } \\
\hline Enterprise service bus & JMS, J2EE, SOAP, XSLT, WSDL, UDDI \\
\hline Development tools & $\begin{array}{l}\text { Eclipse, J2EE, J2SE, J2ME, XML, UML, Java Server } \\
\text { Faces, SWT, XMI, WS BPEL, SQLJ, JDBC, XSLT, } \\
\text { WSDL, UDDI }\end{array}$ \\
\hline Business performance management tools & $\begin{array}{l}\text { W3 Common Log Format, WS DM initiatives, } \\
\text { CEI/CBE }\end{array}$ \\
\hline Interaction services & J2EE, WSEP, VoiceXML \\
\hline Process services & J2EE, BPEL4WS, WSDL, UDDI \\
\hline Information services & XQuery, SQL, JDBC/ODBC \\
\hline Partner services & $\begin{array}{l}\text { FTP, sFTP, HTTP, HTTP/S, RosettaNet, SMTP, JMS, } \\
\text { SOAP/HTTP, WMQ, cXML, EDI }\end{array}$ \\
\hline Business application services & J2EE \\
\hline Application and information assets & J2C, JMS, IIOP, JDBC, IMS, CICS \\
\hline
\end{tabular}

One of the main problems for successful vehicle routing is effective navigation engine. Using service integration approach, an example of navigation engine was implemented. This engine usually is connected to GIS, maps, routing algorithm and customer data engines. To connect these parts, we can use some of the business process management tools, as example Microsoft 
BizTalk, to transmit data through the services, are used the Extensible Markup Language (XML). To develop this integration and create navigation engine service, are used Business Process Execution Language. At all, under this service, we must integrate customer pick-up or delivery request with GIS, then send this data to routing algorithm and at the end send routing information to the map (Fig. 3).

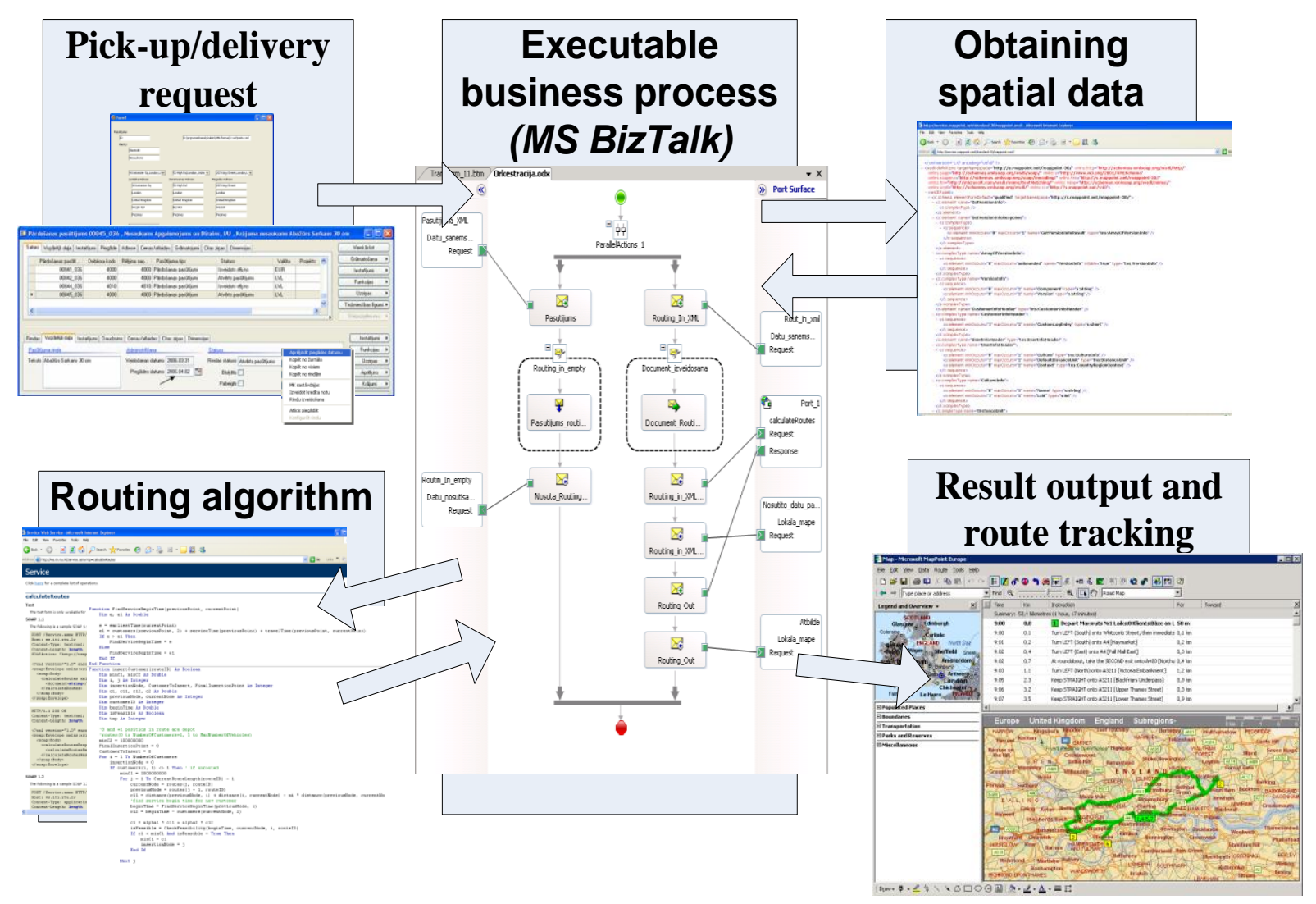

Fig. 3. Example of routing service integration

The received information is stored using auto-generated Eclipse or a Microsoft Axapta form. Then using Microsoft BizTalk BPEL, according to the received data, process obtains spatial data - location, distance etc. This information through business process service is sent to the routing algorithm to calculate best delivery of pick-up sequence and create route information. After that, business process communicates with map service, transfer rout information and display result using MapPoint service.

This is only one part from main control service, but very important and from this result depends if the system will be usable, fast, effective and proper.

\section{Results and discussion}

In this paper, it was attempted to find the best way to integrate different applications used to solve the routing problem at a postal-service provider. Various integration technologies and approaches have been discussed. Effective control of postal pick-up and delivery is very complex process. Therefore, it is difficult to choose the only one best way how to integrate all system components. The goal of effective system is proper rout and pick-up/delivery planning. Effective planning can help save time, work, optimize employment, and monitor car usage. The main conclusion is that the service-oriented integration is the best suited integration approach because of usage of external data sources providing addresses of customers and spatial data. It also allows for easy integration of routing algorithms developed 
by third parties. That allows the postal service to avoid from maintaining extensive spatial data databases and to utilize the state-of-art routing algorithms. However, the process-oriented integration might yield better performance of the integrated solution.

Further research will show the possibilities of service integration for addressing real-time routing in the case of emergency situation and handling of exceptions.

\section{Acknowledgment}

This study was funded by Riga Technical University, Latvia. The author would like to acknowledge Dr.sc.ing. Janis Grabis for his assistance in this paper creation.

\section{Bibliography}

1. Hohpe G., Woolf B. Enterprise integration patterns. Design, Building and deploying messaging solutions. Boston, 2008. p. 1-10.

2. Lam W., Shankararaman V. Enterprise architecture and integration methods, implementation, and technologies. New York, 2007. p. 9-22.

3. Microsoft. Guidelines for Application Integration, patterns and practices. USA, 2003. p. 1-15.

4. Vernadat F.B. Enterprise modeling and integration principles and applications. UK, 1996. p. 9-25.

5. Piera M.A., Guasch A. A Technological platform for designing real-times decision tools in transportation logistics, International Mediterranean Modeling Multiconference, Spain, 2006. p. 111-116.

6. Jung H. et al., Integration of GIS, GPS, and optimization technologies for the effective control of parcel delivery service, Computer \& Industrial Engineering, Special issue: Computational intelligence and information technology applications to industrial engineering selected papers from the $33^{\text {rd }}$ ICC\&IE, 2006. p. $154-162$.

7. Mueller J. Special Edition Using SOAP, Que Publishing, 2001. p. 356 -390.

8. Abraham A., Grosan C., Pedrycz W. Engineering Evolutionary Intelligent Systems, Springer, 2008. p. 379400 